NBER WORKING PAPER SERIES

\title{
THE EFFECT OF MALPRACTICE LIABILITY ON THE DELIVERY OF HEALTH CARE
}

\author{
Katherine Baicker \\ Amitabh Chandra \\ Working Paper 10709 \\ http://www.nber.org/papers/w10709

\section{NATIONAL BUREAU OF ECONOMIC RESEARCH 1050 Massachusetts Avenue Cambridge, MA 02138} \\ August 2004
}

This paper was presented at the National Bureau of Economic Research conference Frontiers in Health Policy on June 24, 2004. This research was funded in part by NIA grant P01 AG19783-02. We are grateful to Alan Garber, Jonathan Skinner, Frank Sloan, Douglas Staiger and conference participants for helpful comments and to Seth Seabury for sharing data. The opinions reflected in this paper are those of the authors and should not be attributed to the NBER or the NIA. The views expressed herein are those of the author(s) and not necessarily those of the National Bureau of Economic Research.

(C2004 by Katherine Baicker and Amitabh Chandra. All rights reserved. Short sections of text, not to exceed two paragraphs, may be quoted without explicit permission provided that full credit, including (C) notice, is given to the source. 
The Effect of Malpractice Liability on the Delivery of Health Care

Katherine Baicker and Amitabh Chandra

NBER Working Paper No. 10709

August 2004

JEL No. I1, K1

\section{$\underline{\text { ABSTRACT }}$}

The growth of medical malpractice liability costs has the potential to affect the delivery of health care in the U.S. along two dimensions. If growth in malpractice payments results in higher malpractice insurance premiums for physicians, these premiums may affect the size and composition of the physician workforce. The growth of potential losses from malpractice liability might also encourage physicians to practice "defensive medicine." We use rich new data to examine the relationship between the growth of malpractice costs and the delivery of health care along both of these dimensions. We pose three questions. First, are increases in payments responsible for increases in medical malpractice premiums? Second, do increases in malpractice liability drive physicians to close their practices or not move to areas with high payments? Third, do increases in malpractice liability change the way medicine is practiced by increasing the use of certain procedures? First, we find that increases in malpractice payments made on behalf of physicians do not seem to be the driving force behind increases in premiums. Second, increases in malpractice costs (both premiums overall and the subcomponent factors) do not seem to affect the overall size of the physician workforce, although they may deter marginal entry, increase marginal exit, and reduce the rural physician workforce. Third, there is little evidence of increased use of many treatments in response to malpractice liability at the state level, although there may be some increase in screening procedures such as mammography.

Katherine Baicker

Department of Economics

Dartmouth College

6106 Rockefeller Hall

Hanover, NH 03755

and NBER

kbaicker@dartmouth.edu

\author{
Amitabh Chandra \\ Department of Economics \\ 6106 Rockefeller Hall \\ Dartmouth College \\ Hanover, NH 03755 \\ and NBER \\ achandra@dartmouth.edu
}




\section{INTRODUCTION}

Recent increases in medical malpractice premiums and malpractice awards to plaintiffs have received much attention in publications as diverse as The New England Journal of Medicine and TIME magazine. ${ }^{1-3}$ Physicians have responded to this cost escalation through a combination of persuasion and protest: by October 2003, the American Medical Association (AMA) declared 19 states to be in "full-blown medical liability crisis” and advocated legislation to establish a $\$ 250,000$ limit to non-economic damages - a position subsequently endorsed by President Bush. ${ }^{4-7}$ More dramatically, surgeons in West Virginia walked off the job to protest the growth of malpractice insurance premiums. ${ }^{8}$ These concerns are not limited to the physician community: a recent survey published in New England Journal of Medicine reported that both physicians and the broader public identified the spiraling costs of malpractice insurance, not medical errors or limited medical coverage, to be the largest and most important problem in the health care system today. ${ }^{3}$

The growth of medical malpractice liability costs has the potential to affect the delivery of health care in the U.S. along two dimensions. First, if growth in malpractice payments results in higher malpractice insurance premiums for physicians, these premiums may affect the size and composition of the physician workforce. While the empirical strength of this relationship has not been conclusively established, a General Accounting Office (GAO) study of seven states concluded that the growth of insurers'

losses from payments is the primary driver of the growth of premiums. ${ }^{9}$ Indeed, the AMA blames the skyrocketing costs of malpractice insurance for the exodus of 
physicians from already underserved rural areas. ${ }^{10}$ Such declines might reduce access to high-quality care for residents in those areas.

Second, the growth of potential losses from malpractice liability might encourage physicians to practice "defensive medicine," ordering more tests and performing more procedures than is economically efficient in order to reduce their malpractice exposure. Previous research has suggested that the current malpractice system is responsible for 5$9 \%$ of medical expenditures by encouraging doctors to practice defensive medicine. ${ }^{11}$ These findings, however, rely on indirect evidence from tort reforms, rather than direct evidence on malpractice costs themselves. Furthermore, it is not clear how these two effects interact, nor what the net effect of liability costs is on patient care.

In this paper we use rich new data to examine the relationship between the growth of malpractice costs and the delivery of health care along both of these dimensions. We pose three questions. First, are increases in payments responsible for increases in medical malpractice premiums? Second, do increases in malpractice liability drive physicians to close their practices? Third, do increases in malpractice liability change the way medicine is practiced by increasing the use of certain procedures? Our analysis suggests that indirect and anecdotal evidence on the size of these effects may be quite misleading.

\section{EMPIRICAL FRAMEWORK}

We use annual state-level data on premiums, payments, physicians, and treatments to explore the long-run effects of changes in physician malpractice liability on the physician workforce and on the practice of medicine. Since tort law is left to the 
purview of the states, physicians within a state are subject to the same legal environment. Furthermore, Sloan et al. (1991, p.148) note that medical malpractice premiums are typically set using data at the state level, and insurance companies that underwrite malpractice policies operate at the state level. ${ }^{12}$ For these reasons, states are a useful unit of aggregation for the study of medical malpractice.

\section{The Effect of Payments on Premiums}

Economic theory and previous empirical studies suggest that there are four primary factors that may explain the rise in malpractice premiums: declines in insurers' investment income (including the presence of an underwriting cycle), a less competitive insurance market, climbing reinsurance rates, and insurer losses from a growing number of malpractice claims and accompanying awards to plaintiffs. ${ }^{2}$ We concentrate primarily on this last factor, as the expected payouts faced by insurers are likely to have a firstorder effect on malpractice premiums. Indeed, this is the view held by both the AMA and the insurance lobby. ${ }^{4,13}$ We return to the potential role of the three other factors in the discussion section below.

We begin by estimating the effect of changes in malpractice payments (through judgments and settlements) on changes in malpractice premiums. We estimate this relationship for average physician premiums as well as for different physician specialties:

$$
\Delta \log (\text { premium })_{i}=\beta_{0}+\beta_{1} \Delta \log (\text { payments })_{i}+\Delta X_{i} \Gamma+\varepsilon_{i}
$$

Payments and premiums are measured per doctor and all variables are measured in logs, thereby allowing the estimated coefficients to be interpreted as elasticities. Equation (1) is estimated in long-differences over time (1993 to 2002) at the state level, weighted by 
state population. To control for time-varying factors, we include changes in the unemployment rate, per capita income, and the mortality rate from flu and malignant neoplasms. Because premiums may adjust somewhat slowly, we lag the payment difference by a year (so that it represents changes between 1992 and 2001), although results are not significantly different if we do not.

Because insurers may operate on a regional basis (and because state-level payments may be noisy), we re-estimate this and subsequent equations also including as regressors the payments made in "neighboring” states. As described below, we create a population-weighted average of the payments made in geographically contiguous states, and include the change of log of payments in this composite neighbor on the right-hand side. These variables will capture the regional spillover effects of payments.

We can also decompose the size of total payments per doctor into two subcomponents, the number of payments per doctor and the size of the average payment:

$$
\begin{aligned}
\Delta \log (\text { premium })_{i}= & \beta_{0}+\beta_{1} \Delta \log (\# \text { payments } / M D)_{i}+ \\
& \beta_{2} \Delta \log (\text { average payment size })_{i}+\Delta X_{i} \Gamma+\varepsilon_{i}
\end{aligned}
$$

This estimate tells us whether premiums are particularly responsive to the number of payments or to the average size of judgments and settlements. For example, if the number of payments captures other costs associated with malpractice cases (such as the fixed costs of preparing for time in court) then premiums may respond more to that factor.

There are several advantages to this long-difference estimation approach. First, the results are robust to the presence of unobservable state-level factors that are fixed and correlated with payments. Another reason to use long-differences is that insurers may 
have knowledge of future liability based on current claims. By examining longdifferences, we incorporate the effects of all of the claims that occur within the nine year interval that we study.

Although this long-difference approach captures long-run trends in liability costs, it does not capture the dynamic adjustment of premiums in response to trends in malpractice payments. While data availability limits our ability to explore the timing of the effect of payments on premiums, we use a state-year panel approach to explore the effect of past and future changes in payments on premium-setting. Sloan et. al (1991, Chapters 6 and 7) show that insurance companies must maintain claim reserves to pay pending claims (without relying on the infusion of new income from premiums), and that malpractice losses exhibit a "long tail" of payments, where payments made on a policy sold in a given year may take up to nine years to be fully realized.. ${ }^{14}$ Premiums charged today may thus reflect both previous payments and forecasts of the potential stream of future payments generated by the policy (as well as complex actuarial forecasts of the macroeconomic and legal environment). To capture the potential effect of past payments on current premiums, we estimate:

$$
\begin{aligned}
\log (\text { premium })_{i t}= & \beta_{i}+\beta_{t}+\beta_{1} \log (\text { payments })_{i t}+\beta_{2} \log (\text { payments })_{i, t-1} \\
& +\beta_{3} \log (\text { payments })_{i, t-2}+\beta_{4} \log (\text { payments })_{i, t-3}+\varepsilon_{i t}
\end{aligned}
$$

where $\beta_{i}$ represents a state fixed effect and $\beta_{t}$ represents a year fixed effect, to account for state- or time-invariant factors. To capture the potential effect of future payments on current premiums, we estimate:

$$
\begin{aligned}
\log (\text { premium })_{i t}= & \beta_{i}+\beta_{t}+\beta_{1} \log (\text { payments })_{i t}+\beta_{2} \log (\text { payments })_{i, t+1} \\
& +\beta_{3} \log (\text { payments })_{i, t+2}+\beta_{4} \log (\text { payments })_{i, t+3}+\varepsilon_{i t}
\end{aligned}
$$


While in theory we could include both leads and lags of payments, the limited time span of our data precludes this. Furthermore, including just the leads is a stronger test of the role of future payments, given the correlation of payments over time: if they are not predictive on their own, they are even less likely to be predictive when lags are accounted for.

The Effect of Malpractice Liability on the Physician Workforce

We next turn to the effect of malpractice liability on the physician workforce. We explore whether states with larger increases in malpractice premiums saw greater declines in the per-capita number of physicians. Implicit in this analysis is the idea that increases in malpractice premiums raise the costs of doing business for physicians and hospitals. The extent to which the increase in costs is borne by physicians (through lower net incomes, hence providing an imperative to leave an area with high premiums) versus patients (through higher prices for physician services or health insurance) will depend on the relative price elasticities of supply and demand. For example, an increase in malpractice premiums will reduce the supply of physicians at each wage. If the demand for physician services is relatively elastic, the increased costs will be borne by physicians through lower net compensation. If the increase in malpractice premiums is "local" (that is, unique to certain areas or states), some physicians might respond to the increased costs and lower compensation by retiring early, or by moving to another state where premiums are lower (which would depress the wages of physicians in that state). If, on the other hand, demand for health services were completely inelastic, then net physician compensation would be unchanged and consumers of health care would bear the cost completely through increases in prices (and, subsequently, health insurance premiums). 
This discussion highlights the extent to which increases in malpractice premiums will not necessarily result in physicians relocating. In fact, many economists believe the latter scenario to be more likely: because of the nature of health insurance (which insulates the patient from the marginal costs of seeking care and which is subsidized by the tax code), the demand for medical services is relatively inelastic. The demand for health services by Medicare beneficiaries is likely to be even less elastic, as they are further insulated from even a wage-fringe benefit tradeoff. There is thus reason to believe that there could be very few physician relocations in response to increases in premiums.

We explore this empirically for physicians (per capita) in different specialties by estimating:

$$
\Delta \log (M D s)_{i}=\beta_{0}+\beta_{1} \Delta \log (\text { premiums })_{i}+\Delta X_{i} \Gamma+\varepsilon_{i}
$$

There are reasons, however, that physicians may respond to more than just the dollar amount of the premium that they face. Being sued imposes other costs on physicians, including lost time at work and psychic costs. ${ }^{15}$ We decompose the physician premium into three subcomponents to see whether physicians respond differentially to different aspects of the liability system: the number of payments per physician (again, through judgments or settlements), the average payment, and the load factor (premiums divided by payments). We thus estimate:

$$
\begin{aligned}
\Delta \log (M D s)_{i}= & \beta_{0}+\beta_{1} \Delta \log (\# \text { payments } / M D)_{i}+\beta_{2} \Delta \log (\text { average payment size })_{i} \\
& +\beta_{3} \Delta \log (\text { load factor })_{i}+\Delta X_{i} \Gamma+\varepsilon_{i}
\end{aligned}
$$

Estimation of equations (4) and (5) allows us to test whether physicians respond to medical malpractice liability costs, and whether they respond simply to the total premium 
or differentially to subcomponents of the premiums. Our long-difference approach again allows us to gauge equilibrium reactions, since we expect that it might take several years for the physician workforce to adjust to changes in malpractice costs.

There are some groups of physicians who may be more sensitive to changes in malpractice liability. First, we examine physicians in two age groups where these effects may be largest: physicians under age 35 (who are most likely to be choosing where to set up their practices) and physicians over age 55 (who are most likely to be choosing whether or when to retire from practice). These physicians entering and exiting the workforce may be more sensitive to changes in premiums than physicians in the middle of their careers with established practices. Second, physicians practicing in rural areas may be particularly sensitive to increases in liability: since malpractice premiums are not typically rated by physician volume, physicians in rural areas will find it difficult to increase the price of their services enough to cover their increased costs (compared to urban physicians with a larger patient base who can spread out the increase in fixed-costs stemming from an increase in malpractice premiums).

\section{The Effect of Malpractice Liability on Treatment}

Finally, we explore the effect of malpractice costs on the treatments patients receive. We analyze several different treatments, including percutaneous coronary interventions, angiography, coronary artery bypass grafts, mammograms, cesarean sections, transurethral prostatectomies for benign prostatic hyperplasia and radical prostatectomies, as well as overall Medicare expenditures. We re-estimate equations (4) and (5) with these dependent variables. Ex ante, the effect of premium increases on the use of these treatments is ambiguous because of potential forces in opposite directions. If 
increases in premiums reduce the number of physicians in an area (on a per capita basis), that could drive overall usage down. If, on the other hand, increases in premiums cause an increase in "defensive medicine," that would drive usage up.

\section{DATA}

We bring several different data sources to bear on these questions, including two new sources of detailed information about medical malpractice liability. We measure all variables at the state-year level and then calculate long differences (in logs). Table 1 provides summary statistics.

\section{Premiums}

We use data on malpractice insurance premiums from an annual survey conducted by the Medical Liability Monitor (MLM). Every year since 1991 the MLM has conducted a nationwide survey of physician malpractice insurance premiums for policies offering \$1 million in coverage for a claim, $\$ 3$ million in total coverage for a year. In a few cases this \$1 million / \$3 million coverage is not available, in which cases the MLM reports premiums for the policies offered. The MLM provides premium data for internal medicine, general surgery and obstetrics-gynecology by state. Often the data are broken down within state for certain geographic regions, typically counties or large metropolitan areas. In these cases we compute a population-weighted average state premium, using population data from the US Census Bureau. Multiple companies reporting premiums for each state in a given year are averaged together, but any companies that did not provide enough information on the geographic breakdown of premiums to compute appropriate weights are dropped. Our final data are comprised of average premiums by specialty and 
state for the periods 1991-1993 and 2000-2003, deflated to real 2000 dollars using the CPI.

Figure 1 shows the changes in premiums by specialty for the 10 largest states. By and large, premiums for different specialties moved together (and up) in each state suggesting that they were driven by system-wide factors within each state (such as the legal environment or the underwriting cycle), rather than by specific technological changes in certain specialties.

\section{Payments}

All malpractice payments made in the United States by or on behalf of a licensed health care provider must be reported to the National Practitioner Data Bank (NPDB) within 30 days under the Health Care Quality Improvement Act of $1986 .{ }^{16}$ Noncompliance is subject to civil penalties codified in 42 U.S.C. 11131-11152.

The NPDB has been the subject of much criticism, from the Physician Insurers Association of America (PIAA) in particular, but also from the GAO. ${ }^{13,17}$ One of the major points of criticism is that the "corporate shield" limits data availability. This loophole exempts payments made on behalf of a hospital or other corporation from inclusion in the NPDB, as long as any individual practitioner is dropped as part of a settlement agreement. ${ }^{17}$ Other concerns about the NPDB include potential underreporting of clinical-privilege restrictions and certain other data fields that are not

relevant for our study. ${ }^{17}$ Even given its limitations, the NPDB is the most representative national database on medical malpractice payments, and therefore the best available data 
for this study.

We examine payments that resulted from either a court judgment against the provider or a settlement made outside of the courts. ${ }^{30}$ The NPDB has information on 250,137 such payments made between September 1, 1990 and December 31, 2003. We restrict our sample to the 50 U.S. states and exclude payments made for Washington DC, areas with missing state information, and other U.S territories. We exclude payments that were linked to dentists, pharmacists, social workers or nurses. In a small fraction of payments, there are multiple physician defendants (and thus multiple reports) but only the total payment by all defendants is reported. In these cases we average the payment over the number of physicians involved. In the NPDB, 5 percent of payments are made by state funds in addition to other payments made by the primary insurer for the same incident. We match such payments based on an algorithm that uses unique physician identifiers, state of work, state of licensure, area of malpractice, type of payment (judgment or settlement) and year of occurrence. We group payments into those resulting from medical treatments (including diagnosis, medication, and other medical treatment), surgical treatments (including surgery and anesthesia), obstetrical treatment, and other

\footnotetext{
* Most previous studies of malpractice awards use a different data source, the Jury Verdict Reporter. There are several systematic reasons that the JVR and the NPDB may differ, all of which make the NPDB more reliable and better suited to this analysis. First, the JVR is not meant to be the universe of awards, with information collected only about an eclectic subset of jury verdicts. Second, amounts recorded in the NPDB measure the amount of actual payments, not jury awards: if a jury awards a plaintiff 1 million dollars, that figure is recorded by JVR - but if a malpractice policy holder only has coverage for a smaller amount (which is what is paid by her insurer), if plaintiffs settle for a lower amount (in order to avoid appeals by the defendant), or if the jury award is reduced in order to comply with state damage caps, the NPDB will record the lower number - which is the number that is relevant for insurance premiums. Third, the JVR reports awards based on the year of the verdict, while the NPDB reports the year in which payments were made. Despite these differences, we compared jury verdicts reported in the NPDB to those from a data set compiled by the RAND Institute for Civil Justice based on the JVR (called the Jury Verdict Database, or JVDB) for New York and California. ${ }^{30}$ Between 1991 and 1999 the JVDB data showed an average annual growth of awards against physicians of 3.9\% in New York (and an average of 42 awards) and $4.3 \%$ in California (and an average of 35 awards), while the NPDB reported average annual growth of $13 \%$ in New York (with an average of 53 awards) and 1.6\% in California (with an average of 43 awards). These results seem reasonably consistent, given the very different sampling frames.
} 
treatments (including monitoring, equipment, intravenous and blood, and all others). We emphasize that it would be misleading to infer anything about negligence from these data, as past work shows a weak correlation between a malpractice claim and negligence. ${ }^{18-22}$

We analyze payments at the state level (overall and by specialty) for 1992-1994 (averaged) and 2000-2002 (averaged). All payment amounts are converted into 2000 dollars. $^{23}$ It is worth noting that increases in payments by specialty within states were not as highly correlated as were increases in premiums.

\section{Physician Workforce}

Data on the number of physicians by specialty and age come from the 2003 Area Resource File (ARF) published by the National Center for Health Workforce Analysis. ${ }^{24}$ The ARF gathers information from the AMA Physician Master File and the County Hospital File and is reported at the county level. If a physician moves and does not inform the AMA of the move, the AMA tracks such physicians through the U.S. Postal Service address correction system. (An alternative to using the ARF data would be utilize physician counts from the U.S. Decennial Census. However, these counts are potentially contaminated by the inclusion of dentists, chiropractors, and veterinarians in the total physician count.) Data from the county level is summed into state measures. For each state, per capita workforce measures are computed by dividing state physician workforce counts by population counts from the Bureau of the Census. Data on the physician workforce by specialty and age are only available for 1989, 1995, 2000, and 2001. Intervening years are linearly interpolated.

Figure 2 shows the increase in physicians per capita by specialty, for all ages and for physicians under age 35, for the 10 largest states. While the number of physicians per 
capita grew in almost all states and specialties, the number of young physicians almost uniformly fell, suggesting that physicians were entering the workforce later and/or working longer. The number of physicians per capita over the age of 55 increased during this period overall.

We also examine the effect of malpractice liability on the subset of rural physicians. The Department of Agriculture’s Economic Research Service categorizes counties based on the size of their urban population and their proximity to metro areas. We classify as "rural” all counties with urban populations of fewer than 20,000 people, and create a subset of doctors (by age and specialty) practicing in such rural counties.

\section{Treatment Rates}

Data on cesarean section rates by state come from the National Center for Health Care Statistics. We have averaged rates by state for 1992-1994 and 1999 and 2002. We gather information on the rates of usage for other procedures from the Dartmouth Atlas of Health Care, based on Medicare Claims data. ${ }^{25}$ We have information on the use of six procedures at the state level for Medicare fee-for-service enrollees over age 65 for 19921993 and 1998-2001, including angiography, coronary artery bypass graft (CABG), percutaneous coronary intervention (PCI), radical prostatectomy and transurethral prostatectomy for benign prostatic hyperplasia for men, and mammograms for women. We also use data on total Medicare expenditures by state. All Medicare measures are adjusted for the age, race, and sex (where appropriate) composition of the state population, and expenditures are measured in real 2000 dollars. $^{25}$ 


\section{Covariates}

Covariates, including per capita income, the unemployment rate, and the mortality rate from flu and malignant neoplasms come from the ARF. Here, too, county-level measures are aggregated to the state level (weighted by county population). When data are only available for some years, values for intervening years are linearly interpolated.

\section{State "Neighborhoods"}

We create composite "neighbors" for each state for our variables of interest based on the population-weighted values of geographically contiguous states. For example, obstetricians in New Hampshire are subject to the ob-gyn premiums in New Hampshire, but may also react to the premiums in neighboring states, so we create a population weighted average of the ob-gyn premiums in Maine, Massachusetts, and Vermont. We use the fixed population from the period before our sample begins to weight the neighbor values, and exclude Alaska and Hawaii from specifications including neighbor variables, as they have no geographically contiguous neighbors.

\section{RESULTS}

We use these data to estimate (1) the relationship between malpractice premiums and payments, (2) the response of the physician workforce to increases in these malpractice costs, and (3) changes in the use of several treatments in response to increases in malpractice costs.

\section{Relationship Between Premiums and Payments}

Surprisingly, there seems to be a fairly weak relationship between malpractice payments (for judgments and settlements) and premiums - both overall and by specialty. 
Table 2 shows the results of estimating equation (1). Each column in the second, third, and fourth panels represents a regression of premiums for MDs in that specialty on payments made for treatments within that specialty. The coefficients cluster around 0.2, and are only marginally significant. Figure 3 shows the regression results from column (1) graphically: a 10\% increase in malpractice payments (per MD) yields a $2.5 \%$ increase in premiums. The third column of each panel includes malpractice payments made in neighboring states as well as payments made within each state. The inclusion of this composite neighbor payment does not affect the estimated coefficients on own payments.

Table 2 also shows the results of estimating equation (2), which decomposes the changes in malpractice payments into two subcomponents: the change in the number of payments and the change in the size of the average payment. Premiums seem roughly equally responsive to each of these components. While premiums do respond to increases in payouts, they do not increase dollar for dollar, suggesting that other factors are at work as well.

Table 3 explores the timing of the effect of malpractice payments on premiums in more detail. Although we have annual data on malpractice payments, because we only have data on premiums for 1991-1993 and 2000-2003, we can only look at the effects of lagged payments or future payments on current premiums for a small time period. We use the 2000-2003 state-year sample to estimate the effect of contemporaneous and lagged payments on premiums, first including only the payments made in each state, and then adding the payments made in neighboring states. We examine both the effect of total malpractice payments made per doctor and the effect of the number of malpractice 
payments made per doctor. The first panel of Table 3 demonstrates that while the evidence is suggestive of a dynamic adjustment process, the coefficients on the lags are not estimated precisely enough to say that they are significantly different from 0 . Estimates of the effect of payments made in neighboring states are not significant, nor do they significantly change the estimates of the effects of own payments.

To study the hypothesis that current premiums reflect future payments we use data from 1991-1994 and report results in the second panel of Table 3b. Analogous to the results that we obtained for prior payments and current premiums, the panel demonstrates that future payments (measured either as the value of payments per physician or as the number of payments per physician) matter even less than lagged values of payments. Ftests for the joint significance of the future value of premiums do not allow us to reject the hypothesis that these variables are jointly zero. Thus, the long-difference specification seems to be the best approach to capturing the long-run effects of changes in malpractice liability.

\section{Relationship Between Malpractice Costs and the Physician Workforce}

We next turn to the relationship between malpractice costs and the size and composition of the physician workforce. Table 4 shows the relationship between malpractice costs and the physician workforce by specialty, age, and rural location. We first examine whether physicians respond to overall premium increases, as in equation (4), and then decompose the response into the three components of premium increases, as in equation (5). We look at the response of all physicians, young physicians, older physicians, and rural physicians, practicing in all areas of medicine and with specialties in obstetrics-gynecology, surgery, and internal medicine. 
The top panel of Table 4 looks at the effect of premiums on physicians based on their age and specialty. On average, the size of the physician workforce in each state does not seem to respond to increases in premiums. (As shown in the third column, these results are insensitive to the inclusion of premiums in neighboring states; other results in the table do not change with its inclusion and are omitted from the table.) For example, a $10 \%$ increase in surgery premiums yields an insignificant $0.1 \%$ decrease in the number of surgeons per capita. Younger and older physicians seem slightly more responsive to increases in premiums, but these responses are small and not consistently statistically significant. These findings are consistent with those of a GAO study which was unable to substantiate claims by provider organizations that rising premiums were dramatically reducing the supply of physicians. ${ }^{26}$

When we decompose increases in premiums into their subcomponents, we see that younger and older physicians seem somewhat more responsive to some subcomponents of increases in premiums, although in most cases we cannot reject the hypothesis that responses to these subcomponents are the same (or that they are zero). Younger and older doctors in general and in ob-gyn seem to respond to increases in the number of cases (as do younger ob-gyns and older internists in particular). Older internists also seem responsive to the size of the average award. The load factor seems to play a smaller role in these decisions. Overall, these results provide weak evidence that some physicians on the margins of their careers make entry and exit decisions in part based on the size and number of malpractice payments.

The bottom panel of Table 4 examines the effect of premium increases on rural physicians. These physicians seem significantly more sensitive to changes in malpractice 
liability. (Again, results do not change with the inclusion of premiums in neighboring states (which are estimated quite imprecisely). There are also no significant differences in the effects of different subcomponents of the premiums, which are omitted from this table.) Overall, a $10 \%$ increase in malpractice premiums results in a $1 \%$ decrease in all rural MDs per capita, and almost a 2\% decrease in older rural MDs. (Because rural MDs comprise only $5 \%$ of all MDs, these results are consistent with the small observed changes in total MDs.) This finding corroborates anecdotal evidence of the particular effect of malpractice liability on rural physicians.

\section{Relationship Between Malpractice Costs and Treatment}

Last, we examine the effect of malpractice costs on the use of cesarean sections and several different treatments for Medicare enrollees over age 65, including angiography, CABG, PCI, radical prostatectomy and transurethral prostatectomy for benign prostatic hyperplasia for men, and mammograms for women, as well as total Medicare expenditures by state. Table 5 summarizes the effects of increases in malpractice costs on the use of cesarean sections, PCI, mammograms, and Medicare expenditures. For the most part, there is little evidence of change in treatment patterns in response to increases in premiums or the subcomponents. (This is consistent with Dubey et. al, who estimate that a $58 \%$ reduction in annual premiums would reduce the number of cesareans performed in the United States by half a percentage point — a very small effect.) $)^{27}$ The results for the other coronary treatments (CABG and angiography) and prostatectomies show similarly small and insignificant effects. (Again, including premiums in neighboring states produces insignificant coefficients and has little effect on the estimated coefficients on own premiums.) 
The use of mammography seems somewhat more sensitive to malpractice costs than the other procedures tested. In particular, mammography rates increase significantly with the average size of payments: when the average malpractice award goes up by $10 \%$, the rate at which mammography is used goes up increases by $4 \%$. (Note that very similar results are obtained when premiums and payments for internal medicine are used, rather than the average across specialties. This is not surprising given the correlation of increases in premiums across specialties. When both average and medicine-specific premium subcomponents are included simultaneously as regressors, the medicinespecific variables have a larger and more significant effect on the use of mammography, but standard errors are large enough that we cannot reject that they are the same.) This sensitivity of the use of a screening procedure seems consistent with anecdotal evidence of changes in physician behavior. Unfortunately we do not have data on other screening procedures with which to generalize this finding.

There is also little increase in overall expenditures for the Medicare population consistent with the fact that the only observed increase in usage appeared in a low-cost screening procedure. This measure serves as a useful proxy for the effect of liability on total medical care. Of course, it could be that decreases in treatment resulting from decreases in the physician workforce in response to increases in liability are being cancelled out by increases in treatment resulting from the practice of more defensive medicine in response to increased liability - but we see little evidence of decreases in the physician workforce. 


\section{Discussion AND Policy IMPLicAtions}

This analysis yields three specific findings. First, past and present malpractice payments do not seem to be the driving force behind increases in premiums. Premium growth may be affected by many factors beyond increases in payments, such as industry competition and the insurance underwriting cycle. Second, increases in malpractice costs (both premiums overall and the subcomponent factors) do not seem to affect the overall size of the physician workforce, although they may deter marginal entry and increase marginal exit and may affect the size of the rural physician workforce. Third, there is little evidence of net increases in the use of the treatments we studied in response to statelevel increases in malpractice costs, although there may be some increase in screening procedures such as mammography.

Our analysis is, however, subject to several limitations. First, while the period we are analyzing saw a substantial increase in malpractice costs, the effect of the recent premium increases on the delivery of healthcare may be different. In the 19 AMAdesignated "crisis states" where premiums have grown dramatically, premiums for a standard professional liability policy (\$1 million per incident, \$3 million per year) for an obstetrician-gynecologist grew by 20\% between 2001 and 2002 in some states (like Connecticut, Illinois, and Kentucky), and by over $50 \%$ in other states (such as Pennsylvania, Arkansas, and Oregon). ${ }^{2}$ In our analysis, premiums grew by an average of 7\% between 1992 and 2002, but there were states that saw much larger increases. For example, over the period of our study average premiums grew by over $30 \%$ in Utah, Nevada, Indiana, Texas and Arkansas. In Texas, premiums for internal medicine physicians grew by $140 \%$. Therefore, our data demonstrates a range of premium growth 
that is comparable to (or perhaps even greater than) the increase in premiums seen in the “crisis" between 2001 and 2002. While this does not in itself imply that the response to the current crisis will be the same as the responses we saw to changes between 1992 and 2002, we have no a priori reason to believe that the response would be different.

Second, we cannot account for the precise mechanism by which current malpractice premiums are driven by past payments or by insurers' expectations of future payments. Our analysis suggests that leads and lags of payments over three years are not predictive of current premiums, but we may not be capturing other related variables whose leads and lags affect current premiums. Insurers have more knowledge about the number and size of claims filed. Furthermore, longer leads and lags than the three years our data allow may prove to be more predictive (although the insensitivity of premiums to the shorter leads and lags casts doubt the strength of this criticism). That said, as Sloan et. al (1991) emphasize, historical data play a central role in guiding expectations of the future in the rate-setting process. To the extent that cumulative expectations about future payments are accounted for by our long-difference approach, this limitation will not be a major source of bias. Nevertheless, we note that if insurers do indeed use alternative sources of information about payments (that are not based on historical or realized payments) in setting premiums, our analysis may understate the degree to which payments affect premiums.

Third, our study is not designed to explore other factors (besides increases in payouts) that may have driven increases in premiums. Another factor analyzed in previous studies is the role of secular declines in insurer investment income (which are different from idiosyncratic declines in such income for a given insurer). State insurance 
regulations often adjust premiums based on expected investment returns - thus mandating that premiums respond to changes in investments, not just changes in expected payouts. $^{\dagger}$ This relationship between premiums and expected payouts could also be generated by a simple model of the malpractice insurance market where the insurer receives net income both from underwriting malpractice insurance and from the float on the premiums (invested in bonds or other investments). The insurer would therefore have revenues from the sum of premiums and the investment income that accrued on these premiums. Simultaneously, the insurer incurs the costs of payments made to settle claims (as well as administrative costs). If the market for such insurers is competitive, all firms will earn zero economic profits. Premiums charged to physicians will depend on expected returns and not historical returns_-a company that loses more money on past investments (when the industry as a whole has not lost money on past investments) will not be able to raise its customers' premiums in the future, but premiums may increase if all companies expect lower future returns.

Fourth, our state-level analysis generates some mismeasurement in the use of different procedures, since patients may travel across state lines for treatment. This potential mismeasurement would tend to bias our results towards zero. However, our analysis was weighted by state population, and cross-state migration is less of a concern for the large states such as California, New York and Illinois. This state-level analysis will also fail to capture treatment changes and physician movements within states in

\footnotetext{
${ }^{\dagger}$ According to the GAO, between 1998 and 2001 insurers realized drastic declines in income from bond holdings (with over 70 percent of insurers' portfolios invested in bonds). ${ }^{9} \quad$ They estimate that the 1.6 percentage point decline in investments that most insurers witnessed between 2000 and 2002 would have raised premiums by over 7 percent. This estimate may represent a lower bound of the effect of declines in investment income on premiums, since insurers may have anticipated the longer secular decline in interest rates. With the decline in bond yields expected to continue, it is perhaps unsurprising that premiums have risen.
} 
response to local variation in premiums, although, as discussed above, many state-wide factors affect premium rates.

Fifth, we have by no means captured the universe of treatments that patients receive that may respond to changes in malpractice costs. For example, while we do not find evidence of large defensive medicine effects for selected procedures involving infants or the elderly, it is possible the greatest manifestations of this effect occur for other patients or for other specific procedures. The addition of data on the use of other treatments on other groups of patients would increase the generality of our results. We also reserve for future work the question of whether increases in malpractice premiums are being passed on to patients through higher costs for physician services or health insurance premiums.

Last, and perhaps most importantly, our estimates may not capture the systemic effects of the current national malpractice liability environment. If doctors react similarly to malpractice payments and premiums within their own state as they do to those in other states, then looking at differences between states will radically underestimate the effect of malpractice liability on the practice of defensive medicine. We thus cannot infer from these results that there is no defensive medicine - rather, only that local differences in malpractice costs do not produce local differences in the physician workforce or the use of these treatments.

While our study does not speak directly to the effect of malpractice reforms, it does provide insight into the mechanisms through which those reforms are likely (and unlikely) to operate. Previous research by Kessler and McClellan found that states that implemented tort reform saw declines in the use of defensive medicine for the treatment 
of heart attacks (although a Harvard malpractice study did not see any effect of threats of litigation on defensive medicine, and a more recent CBO study was unable to confirm the general nature of the Kessler-McClellan result). ${ }^{11,28,}{ }^{29}$ Our analysis suggests that changes in the physician workforce in response to reduced malpractice liability is not a mechanism through which state-level tort reform is likely to affect the practice of medicine. In our data, we do see lower premium and payment growth in states that had adopted tort reforms or damage caps before the mid-1990s, but we do not find that such states have higher physician growth. Unfortunately, the scope of our analysis (which uses data from the period after the passage of most state tort reform measures) precludes a direct evaluation of the effect of tort reform on the delivery of health care.

The fact that we see very little evidence of widespread physician exodus or dramatic increases in the use of defensive medicine in response to increases in state malpractice premiums places the more dire predictions of malpractice alarmists in doubt. The arguments that state tort reforms will avert local physician shortages or lead to greater efficiencies in care are not supported by our findings. 


\section{REFERENCES}

1. Eisenberg D, Sieger M. The doctor won’t see you now. TIME; 2003.

2. Mello MM, Studdert DM, Brennan TA. The new medical malpractice crisis. $N$ Engl J Med. Jun 5 2003;348(23):2281-2284.

3. Blendon RJ, DesRoches CM, Brodie M, et al. Views of Practicing Physicians and the Public on Medical Errors. New England Journal of Medicine. December 12 2002;347(12):1933-1940.

4. American Medical Association. The Medical Liability Crisis: Talking Points. Available at: http://www.ama-assn.org/ama1/pub/upload/mm/399/mlr_tp.pdf. Accessed April 29th, 2004.

5. American Medical Association. Confronting the Myths on Medical Liability Reform. 2004. Available at: http://www.amaassn.org/ama1/pub/upload/mm/399/mlrmyths.pdf. Accessed May 2nd, 2004.

6. American Medical Association. The Medical Liability Crisis: Why Repealing the McCarran-Ferguson or Passing Other Insurance Laws is Not the Answer. Available at: http://www.ama-assn.org/ama1/pub/upload/mm/399/mlrcrisis.pdf. Accessed May 2nd, 2004.

7. CNN. Bush Outlines Medical Liability Reform. Available at: http://www.cnn.com/2003/ALLPOLITICS/01/16/bush.malpractice/index.html. Accessed October 20th, 2003.

8. CNN. W.Va. doctors strike over insurance costs. Available at: http://www.cnn.com/2003/HEALTH/01/01/medical.malpractice/index.html. Accessed October 20th, 2003.

9. United States. General Accounting Office. Medical Malpractice Insurance: Multiple factors have contributed to increased premium rates. Washington, D.C.: U.S. General Accounting Office; 2003.

10. Nelson JC. Dying for Help: Are Patients Needlessly Suffering Due to the High Cost of Medical Liability Insurance? October 12003.

11. Kessler DP, McClellan MB. Do Doctors Practice Defensive Medicine? Quarterly Journal of Medicine. 1996 1996;111(2):353-390.

12. Thorpe KE. The Medical Malpractice 'Crisis': Recent Trends and the Impact of State Laws. Health Aff (Millwood). 21 January 2004:W20-W30.

13. Smarr LE. Statement of the Physician Insurers Association of America before a joint hearing of the United States Senate Judiciary Committee and the Heath, Education, Labor and Pensions Committee. Available at: http://www.thepiaa.org/pdf_files/February_11_Testimony.pdf. Accessed May 2nd, 2004.

14. Sloan F, Bovbjerg RR, Githens PB. Insuring Medical Malpractice. New York, NY: Oxford University Press; 1991.

15. Kessler DP, McClellan MB. How Liability Law Affects Medical Productivity. Journal of Health Economics. 2002;21:931-955.

16. United States. Department of Health and Human Services., Health Resources and Services Administration. Bureau of Health Professions., Division of Practitioner Data Banks. National Practitioner Data Bank Public Use Data File; 2004. 
17. United States. General Accounting Office. Major Improvements are Needed to Enhance Data Bank's Reliability. Washington, D.C.; 2000.

18. Localio AR, Lawthers AG, Brennan TA, et al. Relation between malpractice claims and adverse events due to negligence. Results of the Harvard Medical Practice Study III. N Engl J Med. Jul 25 1991;325(4):245-251.

19. Weiler PC, Hiatt H, Newhouse JP, Johnson WG, Brennan TA, Leape LL. A Measure of malpractice : medical injury, malpractice litigation, and patient compensation. Cambridge, Mass.: Harvard University Press; 1993.

20. Thomas EJ, Lipsitz SR, Studdert DM, Brennan TA. The reliability of medical record review for estimating adverse event rates. Ann Intern Med. Jun 4 2002;136(11):812-816.

21. Thomas EJ, Studdert DM, Burstin HR, et al. Incidence and types of adverse events and negligent care in Utah and Colorado. Med Care. Mar 2000;38(3):261271.

22. Studdert DM, Thomas EJ, Burstin HR, Zbar BI, Orav EJ, Brennan TA. Negligent care and malpractice claiming behavior in Utah and Colorado. Med Care. Mar 2000;38(3):250-260.

23. United States. Department of Commerce., Bureau of Economic Analysis. Gross Domestic Product: Implicit Price Deflator. Available at: http://research.stlouisfed.org/fred2/data/GDPDEF.txt. Accessed May 2nd, 2004.

24. National Center for Health Workforce Analysis, Department of Health and Human Services. Area Resource File; 2003.

25. Wennberg J, Cooper M. The Dartmouth Atlas of Health Care: American Hospital Association Press; 1999.

26. United States. General Accounting Office. Implications of Rising Premiums on Access to Health Care. Washington D.C.: U.S. General Accounting Office; 2003.

27. Dubay L, Kaestner R, Waidmann T. The Impact of Malpractice Fears on Cesarean Section Rates. Journal of Health Economics. August 1999;18:491-522.

28. Congressional Budget Office. Limiting Tort Liability for Medical Practice. Available at: http://www.cbo.gov/showdoc.cfm?index=4968\&sequence $=0$. Accessed June 21, 2004.

29. Harvard Medical Practice Study. Patients, Doctors, and Lawyers: Medical Injury, Malpractice Litigation, and Patient Compensation in New York. Boston: Harvard University School of Public Health; 1990:Chapter 10.

30. Peterson, Mark A. and Priest, George L., The Civil Jury: Trends in Trials and Verdicts, Cook County, Illinois, 1960-1979, RAND, R-2881-ICJ, 1982.

31. Chandra A, Nundy S, Seabury SA. 2004. The Growth of Physician Malpractice Liability. Manuscript. Department of Economics, Dartmouth College. 


\section{Figure 1: Growth in PremiUms (10 LARgest States)}

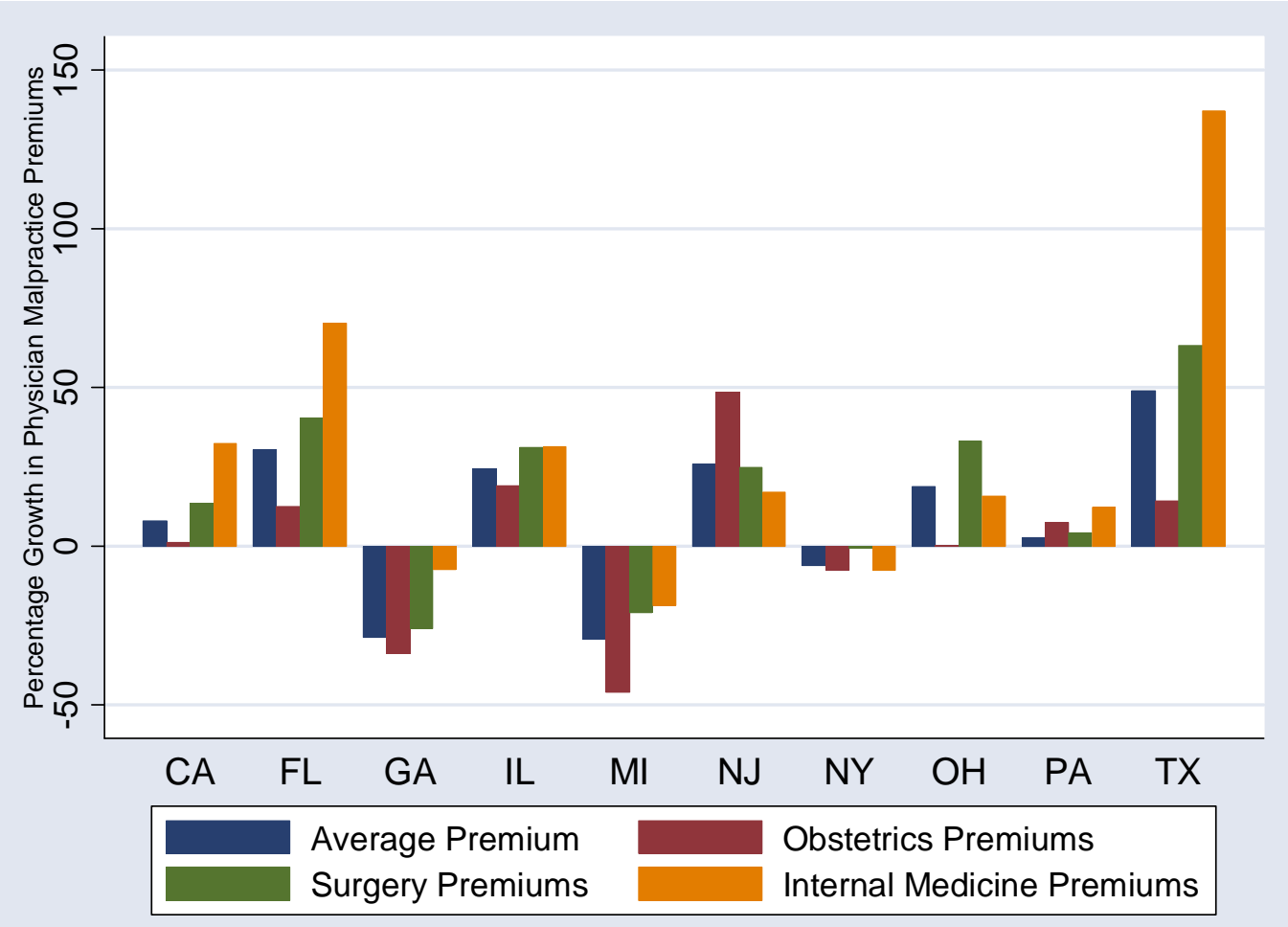

Notes: Premium data come from the National Liability Monitor. Bars represent the percentage growth in physician premiums by specialty between 1991-1993 (averaged) and 2000-2002 (averaged) for the ten largest states. 
Figure 2: Change in Physician Workforce (10 LARgest States)
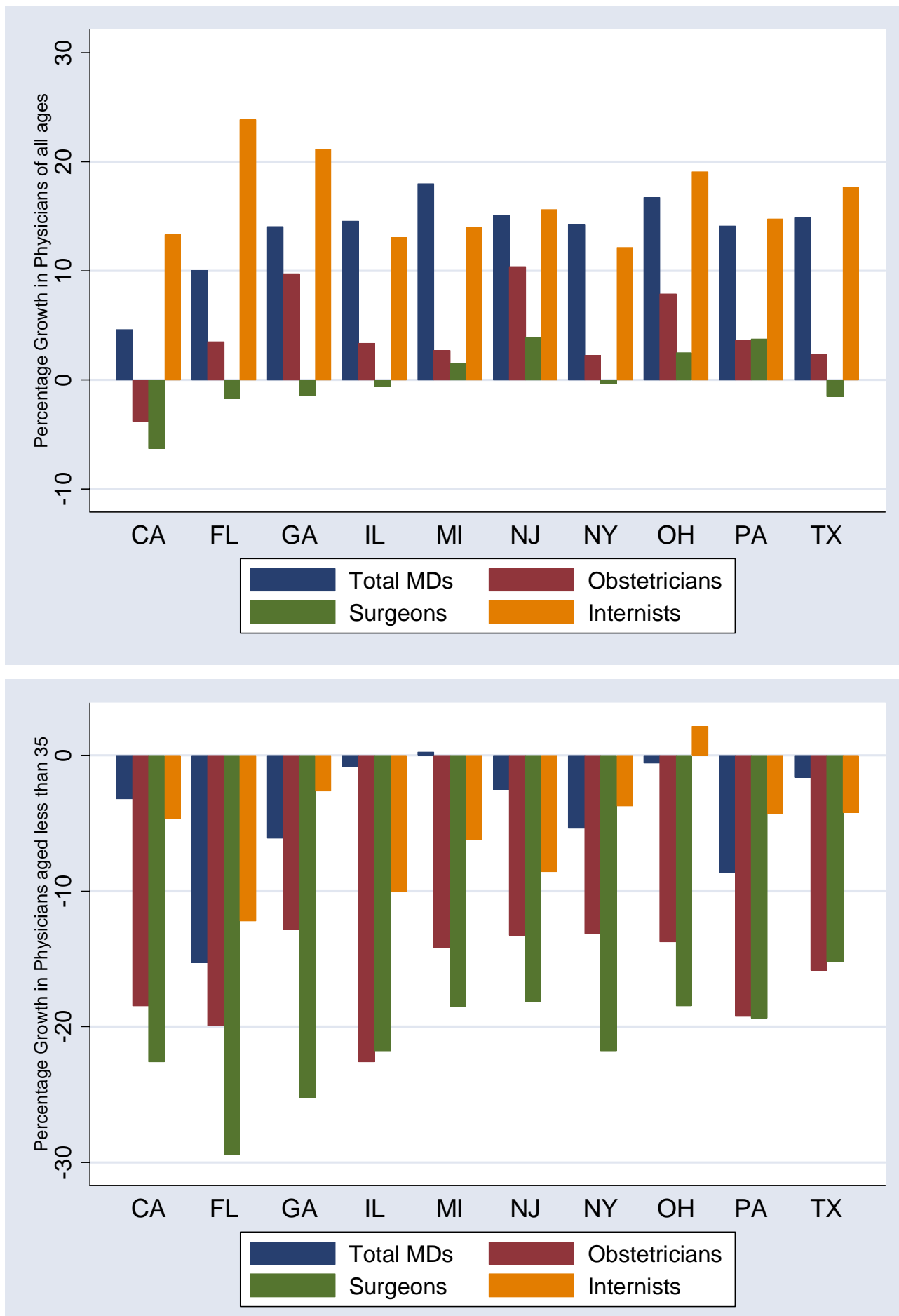

Notes: Physician workforce data come from the Area Resource File. Bars represent the percentage growth in physicians by specialty between 1993 and 2001 for the 10 largest states. 
Figure 3: RELATIONSHIP BETWEEN PAYMENTS AND PREMIUMS

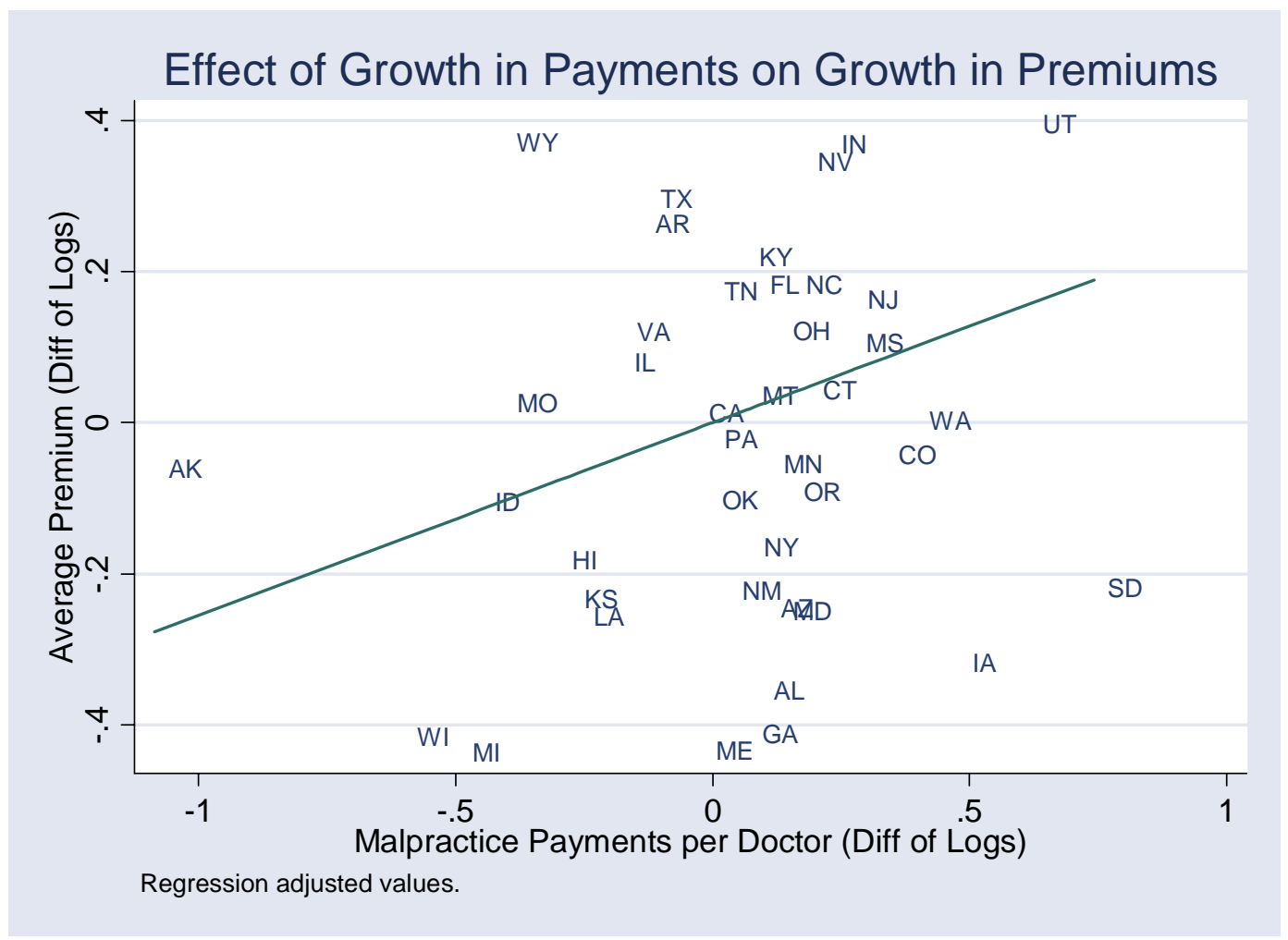

Notes: Premium data come from the Medical Liability Monitor, and y-axis shows the difference between the log of premiums per doctor for 1992-93 (averaged) and 2001-2002 (averaged). Payment data come from the National Practitioner Data $B a n k$, and the x-axis represents the difference between the log of payments per doctor in 1991-1992 (averaged) and 2000-2001 (averaged). The regressionadjusted values shown are net of changes in the log of the states' unemployment rate and income, as well as deaths from flu and malignant neoplasms. The line represents the result of a regression of the difference in logs of premiums on the difference in logs of payments, controlling for these covariates, and has a slope of 0.255 (s.e.0 .182), shown in Table 2. 
Table 1: Summary Statistics

\begin{tabular}{|c|c|c|c|c|}
\hline & \multicolumn{2}{|c|}{ Level in 2001} & \multicolumn{2}{|c|}{$\begin{array}{c}\text { Percent Growth } \\
1993-2001\end{array}$} \\
\hline & Mean & Std. Dev. & Mean & Std. Dev. \\
\hline \multicolumn{5}{|l|}{ Medical Malpractice } \\
\hline Average & 28374 & 12627 & 10.7 & 24.1 \\
\hline Surgery & 34360 & 15272 & 17.3 & 27.2 \\
\hline Ob-Gyn & 52374 & 22504 & 2.3 & 22.4 \\
\hline Internal Medicine & 10422 & 5270 & 30.2 & 42.2 \\
\hline \multicolumn{5}{|l|}{ Payments } \\
\hline All & 13.2 & 7.7 & 4.3 & 31.5 \\
\hline Surgery & 3.4 & 2.0 & 11.4 & 91.3 \\
\hline Ob-Gyn & 1.9 & 1.3 & 9.9 & 58.4 \\
\hline Medicine & 7.7 & 4.7 & 8.2 & 32.7 \\
\hline \multicolumn{5}{|l|}{ Procedure Rates } \\
\hline Angiography & 21.9 & 3.8 & 37.4 & 14.1 \\
\hline CABG & 6.2 & 0.9 & 19.3 & 9.8 \\
\hline PCI & 9.4 & 1.7 & 95.6 & 35.7 \\
\hline TURP & 6.8 & 0.8 & -0.5 & 0.0 \\
\hline Radical Prostatectomy & 1.6 & 0.4 & -40.8 & 9.7 \\
\hline Mammography & 35.3 & 3.2 & 77.4 & 23.7 \\
\hline Cesareans & 24.0 & 2.4 & 11.1 & 6.5 \\
\hline Medicare Expenditures & 6188.8 & 882.2 & 28.2 & 8.0 \\
\hline \multicolumn{5}{|l|}{ MDs (per thousand pop) } \\
\hline Total & 25.3 & 6.1 & 14.2 & 6.0 \\
\hline Rural & 1.3 & 1.3 & 0.0 & 15.8 \\
\hline Surgery & 5.4 & 1.0 & 1.8 & 6.4 \\
\hline Ob-Gyn & 1.3 & 0.3 & 5.8 & 7.6 \\
\hline Internal Medicine & 3.5 & 1.4 & 17.6 & 7.0 \\
\hline
\end{tabular}

Notes: $\quad$ Summary statistics are weighted by population in 2001.

Observations are at the state-year level, with percent growth calculated for 1993 to 2001. Payment data are 3-year averages for 1992-1994 and 2000-2002. Premium data are 2year averages for 1992-1993 and 2001-2002. Physician data for 1993 are interpolated using 1989 and 1995 observations. Treatments are calculated from 1992-1993 data and 1998-2001 data.

Physician data come from the Area Resource File based on the AMA Master file. Premiums come from Medical Liability Monitor. Payments Come from the National Practitioner Data Bank. Covariates come from the Area Resource File. Treatment rates and Medicare expenditures come from the Dartmouth Atlas of Health Care. 
Table 2: Effect of Malpractice Payments on Premiums

All measures represent differences of logs, 1993 to 2001

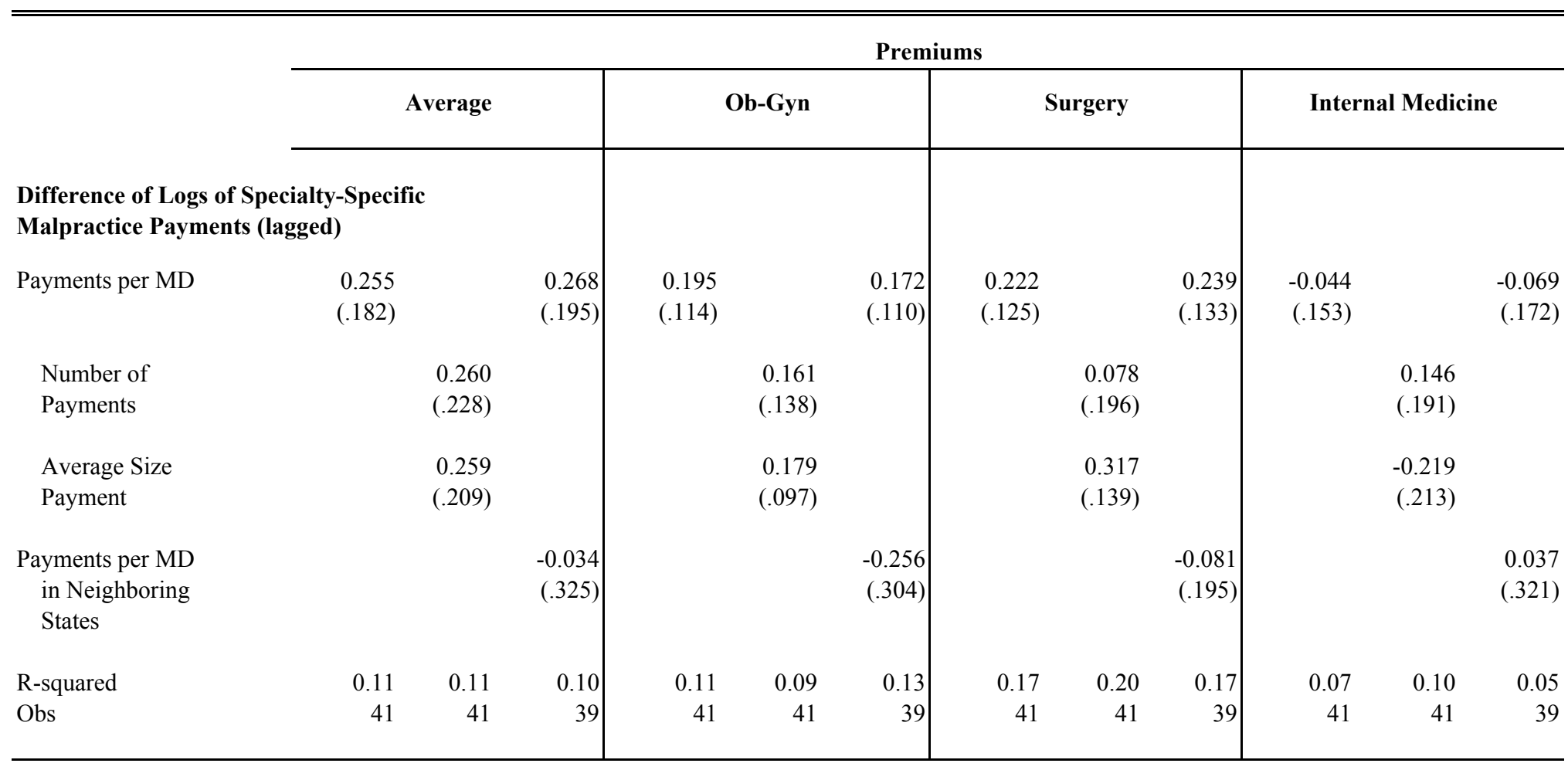

Notes:

Dependent variables are all measured as differences in logs between 1993 and 2002 at the state level. Independent variables are differences in logs between 1992 and 2001.

Premiums and payments both measured per MD.

Premiums come from Medical Liability Monitor. Payments Come from the National Practitioner Data Bank. Covariates come from the Area Resource File.

Regressions are weighted by population in 2001. Robust standard errors in parentheses.

Covariates include growth in unemployment rate, per capita income, and deaths from malignant neoplasms and flu. 
Table 3: Timing and the Effect of Payments on Premiums

\begin{tabular}{|c|c|c|c|c|c|c|c|c|c|}
\hline \multicolumn{10}{|c|}{ Dependent Variable: Log of Premiums } \\
\hline \multicolumn{5}{|c|}{ Effect of lagged payments (in logs) } & \multicolumn{5}{|c|}{ Effect of future payments (in logs) } \\
\hline & \multicolumn{2}{|c|}{$\begin{array}{l}\text { Total Payments } \\
\text { per MD }\end{array}$} & \multicolumn{2}{|c|}{$\begin{array}{c}\text { Number of } \\
\text { Payments per MD }\end{array}$} & & \multicolumn{2}{|c|}{$\begin{array}{l}\text { Total Payments } \\
\text { per MD }\end{array}$} & \multicolumn{2}{|c|}{$\begin{array}{c}\text { Number of } \\
\text { Payments per MD }\end{array}$} \\
\hline Payments, period t & $\begin{array}{l}0.023 \\
(.046)\end{array}$ & $\begin{array}{l}0.024 \\
(.053)\end{array}$ & $\begin{array}{r}2.386 \\
(2.702)\end{array}$ & $\begin{array}{r}2.270 \\
(2.688)\end{array}$ & Payments, period $\mathrm{t}$ & $\begin{array}{r}-0.082 \\
(.045)\end{array}$ & $\begin{array}{r}-0.092 \\
(.066)\end{array}$ & $\begin{array}{r}2.386 \\
(3.645)\end{array}$ & $\begin{array}{r}2.728 \\
(4.453)\end{array}$ \\
\hline Payments, period t -1 & $\begin{array}{l}0.052 \\
(.041)\end{array}$ & $\begin{array}{l}0.046 \\
(.045)\end{array}$ & $\begin{array}{r}-0.030 \\
(.059)\end{array}$ & $\begin{array}{r}-0.059 \\
(.061)\end{array}$ & Payments, period $t+1$ & $\begin{array}{r}-0.038 \\
(.061)\end{array}$ & $\begin{array}{r}-0.058 \\
(.081)\end{array}$ & $\begin{array}{l}0.007 \\
(.083)\end{array}$ & $\begin{array}{l}0.010 \\
(.086)\end{array}$ \\
\hline Payments, period $\mathrm{t}-2$ & $\begin{array}{l}0.096 \\
(.047)\end{array}$ & $\begin{array}{l}0.071 \\
(.050)\end{array}$ & $\begin{array}{l}0.064 \\
(.066)\end{array}$ & $\begin{array}{l}0.079 \\
(.069)\end{array}$ & Payments, period $\mathrm{t}+2$ & $\begin{array}{l}0.016 \\
(.064)\end{array}$ & $\begin{array}{r}-0.023 \\
(.074)\end{array}$ & $\begin{array}{l}0.104 \\
(.073)\end{array}$ & $\begin{array}{l}0.029 \\
(.084)\end{array}$ \\
\hline Payments, period $\mathrm{t}-3$ & $\begin{array}{r}0.090 \\
(.048)\end{array}$ & $\begin{array}{l}0.084 \\
(.055)\end{array}$ & $\begin{array}{r}-0.065 \\
(.071)\end{array}$ & $\begin{array}{r}-0.017 \\
(.078)\end{array}$ & Payments, period $\mathrm{t}+3$ & $\begin{array}{l}0.037 \\
(.062)\end{array}$ & $\begin{array}{l}0.009 \\
(.074)\end{array}$ & $\begin{array}{l}0.164 \\
(.079)\end{array}$ & $\begin{array}{l}0.098 \\
(.082)\end{array}$ \\
\hline $\begin{array}{l}\text { Pymts in Neighboring } \\
\text { States, period } t\end{array}$ & & $\begin{array}{l}0.026 \\
(.120)\end{array}$ & & $\begin{array}{l}10.464 \\
(8.618)\end{array}$ & $\begin{array}{l}\text { Pymts in Neighboring } \\
\text { States, period t }\end{array}$ & & $\begin{array}{l}0.040 \\
(.122)\end{array}$ & & $\begin{array}{r}3.435 \\
(8.819)\end{array}$ \\
\hline $\begin{array}{l}\text { Pymts in Neighboring } \\
\text { States, period } \mathrm{t}-1\end{array}$ & & $\begin{array}{r}-0.145 \\
(.146)\end{array}$ & & $\begin{array}{l}0.149 \\
(.164)\end{array}$ & $\begin{array}{l}\text { Pymts in Neighboring } \\
\text { States, period } t+1\end{array}$ & & $\begin{array}{l}0.119 \\
(.141)\end{array}$ & & $\begin{array}{r}-0.042 \\
(.153)\end{array}$ \\
\hline $\begin{array}{l}\text { Pymts in Neighboring } \\
\text { States, period } \mathrm{t}-2\end{array}$ & & $\begin{array}{r}-0.163 \\
(.127)\end{array}$ & & $\begin{array}{r}-0.063 \\
(.184)\end{array}$ & $\begin{array}{l}\text { Pymts in Neighboring } \\
\text { States, period } t+2\end{array}$ & & $\begin{array}{l}0.209 \\
(.125)\end{array}$ & & $\begin{array}{l}0.278 \\
(.165)\end{array}$ \\
\hline $\begin{array}{l}\text { Pymts in Neighboring } \\
\text { States, period t-3 }\end{array}$ & & $\begin{array}{r}-0.176 \\
(.132)\end{array}$ & & $\begin{array}{l}0.011 \\
(.158)\end{array}$ & $\begin{array}{l}\text { Pymts in Neighboring } \\
\text { States, period } t+3\end{array}$ & & $\begin{array}{r}-0.198 \\
(.174)\end{array}$ & & $\begin{array}{l}0.108 \\
(.137)\end{array}$ \\
\hline State and Year FEs & yes & yes & yes & yes & State and Year FEs & yes & yes & yes & yes \\
\hline Observations & 197 & 189 & 113 & 109 & Observations & 197 & 189 & 113 & 109 \\
\hline R-squared & 0.959 & 0.961 & 0.957 & 0.959 & R-squared & 0.957 & 0.959 & 0.948 & 0.950 \\
\hline Probability own lags jointly 0 & 0.069 & 0.194 & 0.575 & 0.513 & Probability own lags jointly 0 & 0.608 & 0.870 & 0.135 & 0.568 \\
\hline Probability all neighbor vars 0 & & 0.510 & & 0.578 & Probability all neighbor vars 0 & & 0.411 & & 0.220 \\
\hline
\end{tabular}

Notes:

Premiums and payments both measured per MD at the state year level in logs, 2000-2003 (for lag specification) or 1990-1993 (for lead specification). Robust standard errors in parentheses.

Premiums come from Medical Liability Monitor. Payments Come from the National Practitioner Data Bank.

Each state's composite neighbor is a population-weighted average of geographically contiguous states. 
Table 4 Effect of Malpractice on Physician Workforce

All measures represent differences of logs, 1993 to 2001

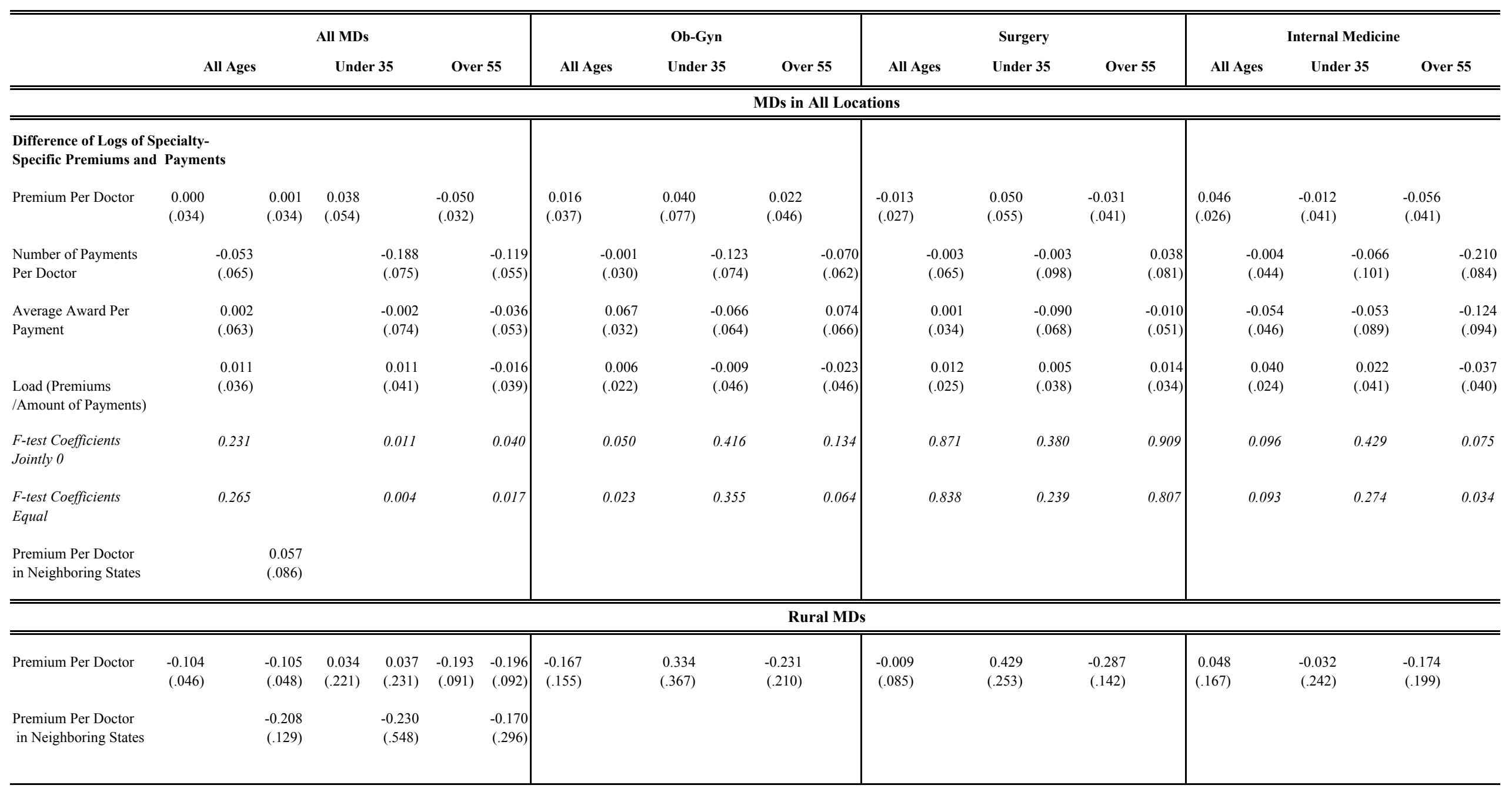

Notes:

Dependent and independent variables are all measured as differences of logs between 1992 and 2001 at the state level. Regressions are weighted by population in 2001 . Robust standard errors in parentheses.

Covariates include growth in unemployment rate, per capita income, and deaths from malignant neoplasms and flu.

Physician data come from the Area Resource File based on the AMA Master file. Premiums come from Medical Liability Monitor. Payments Come from the National Practitioner Data Bank. Covariates come from the Area

Resource File. 
Table 5: Effect of Malpractice on Patient Care

All measures represent differences of logs, 1993 to 2001

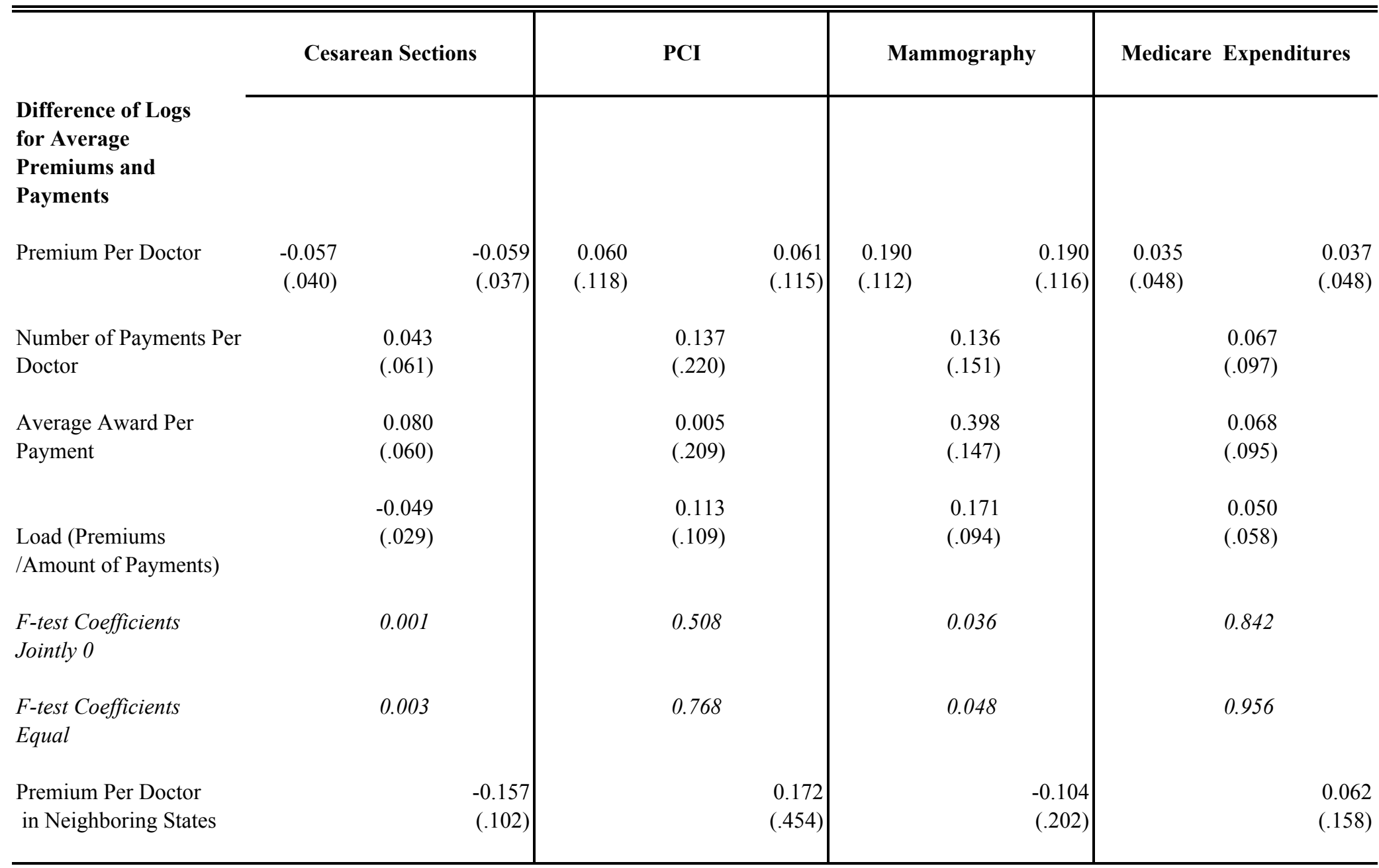

Notes:

Dependent and independent variables are all measured as difference in logs between 1992 and 2001 at the state level. Regressions are weighted by population in 2001. Robust standard errors in parentheses.

Covariates include growth in unemployment rate, per capita income, and deaths from malignant neoplasms and flu.

Treatment rates and Medicare expenditures come from the Dartmouth Atlas of Health Care. Premiums come from Medical Liability Monitor.

Payments Come from the National Practitioner Data Bank. Covariates come from the Area Resource File. 